\title{
Building material capabilities: A socio-technical analysis of composite product development and manufacturing strategy
}

\author{
Anna P. Chatzimichali*, Kevin D. Potter \\ Aerospace Engineering Department, \\ Advanced Composites Centre for Innovation and Science, \\ University of Bristol, Queen's Building, \\ University Walk, Bristol, BS8 1TR, UK \\ Email: a.chatzimichali@bristol.ac.uk \\ Email: k.potter@bristol.ac.uk \\ *Corresponding author
}

\begin{abstract}
The development of advanced material requires much more than purely technical knowledge. This paper presents a socio-technical analysis of industrial capability issues for composites material product. The central idea behind this work is to provide a framework to identify and examine important growth drivers in composites. Composites are engineered materials, made from a combination of constituent materials with different properties, find applications in a variety of business sectors and contribute towards a sustainable economy. The main goal of this paper is to shed some light on how the composites industry could accelerate production rates, meet demands for sophisticated products in high volumes and reach advanced levels of industrialisation.
\end{abstract}

Keywords: composite material technologies, composite product development, manufacturing strategy, material industrialisation.

Reference to this paper should be made as follows: Chatzimichali, A.P., Potter, K.D. (2014) 'Building material capabilities: A sociotechnical analysis of composite product development and manufacturing strategy', Int. J. Markets and Business Systems, Vol. x, No. $\mathrm{x}, \mathrm{pp} . \mathrm{xxx}-\mathrm{xxx}$.

Biographical notes: Anna Chatzimichali gained her MEng and $\mathrm{PhD}$ in Production Engineering and Management from Democritus University of Thrace in 2005 and 2010, respectively. She undertook full time research positions in Instituto Superior Téchnico, Maastricht University and TU Delft. Currently she is a Research Associate in University of Bristol investigating issues of manufacturing strategy for composites material products.

Kevin Potter gained his BSc in Materials Science from Imperial College of Science and Technology in 1974, and since then he has spent almost all his career working with the design, manufacture and assessment of composite products. Since joining the University of Bristol in 1995, he has been responsible for developing and running a number of research programmes in the general area of materials.

This paper is a revised and expanded version of a paper entitled 'Growth through material: an exploratory study in the development of the composite industry' 


\section{Materials and technology development}

Materials in general, play a crucial role in the design, manufacturing and utilisation of products and their components. A material can act as an enabling technology, pertaining to various sectors and markets and at the same time creating radical changes in industrial capabilities and performance. But is the availability of a new material technology enough to create sustainable industrial growth? In this paper we argue that an industrial growth model requires a holistic consideration of issues around material technologies. The aim of this work is to develop an overarching theoretical framework to understand the conceptual themes related with industrial growth as they are perceived by practitioners and experts in the field of a relative new material technology.

Composites have the potential to revolutionise high value industrial sectors and yield very significant benefits in industries such as aerospace, automotive, wind energy, marine and construction. Composite materials - materials made from at least two materials that together produce advanced properties different from the monolithic materials that created them - are contributing to the development of more durable, lightweight and higher performance products, and help to deliver a low-carbon and thus more sustainable economy.

Despite the importance of materials, there is hardly any research at the industrial ecosystem level regarding the effects of advanced materials on manufacturing strategy and industrial growth. Literature on technology development barely covers those considerations. The dominant design, defined as the emergence of a dominant technology in an industry (Utterback and Abernathy, 1975; Saviotti and Metcalf, 1984; Anderson and Tushman, 1990, 1991; Tushman and Rosenkopf, 1992 Utterback and Suarez, 1993), is a theoretical construct unable to describe material technologies. This term connects a dominant design with a single market, while the fundamental nature of a material technology impacts a variety of sectors and markets. Moreover, when a dominant design emerges, activities in an organisation shift the focus from product innovation to process innovation (Abernathy and Utterback, 1978). This product - process innovation perspective fails to capture the dynamics of industrial growth through materials, especially when the material and product are created simultaneously, like in composite material technologies. This concurrent development implies that the product and process should also get industrialised simultaneously. A similar pattern of simultaneously product and process innovation has been identified by (Linton and Walsh, 2008) for another enabling technology, nanotechnology.

Another point related to the dominant design approach is the hierarchy of the design (system level, first-order subsystem, second order subsystem, component level), according to Murman and Frenken (2006). Each level in this artefact hierarchy can follow its own technology cycle. However, the material of a product is not a part of this systemic hierarchy. The material is an attribute and therefore material changes can potentially redefine the whole systemic hierarchy in a product. Consequently, this type of theory around dominant design and technological change cannot adequately describe composites or, more general material-based technologies.

At the industrial structure level the shape of the industry seems to differ with theories of technological growth. According to Utterback and Suarez (1993), when a dominant design 
is established, the number of firms in the sector declines and only a few large firms remain. Looking back at the industrial history of composites, the opposite appears to be true. The vertically integrated organisations, holding the facilities and all necessary skills in-house, that used to dominate the industrial landscape in the late '80s (Harris, 1991), gave their place to today's more fragmented supply chain, where small and medium enterprises are very typical.

It is important to create a set of grounded theoretical concepts and sketch their relationships in order to understand the impact of composites on product development, manufacturing and overall industrial growth. For this purpose, this qualitative study was designed to examine the factors that block or facilitate the development and industrialisation of composite material products. Section 2, discusses the characteristics of composite material technologies along with current production capability issues. The specifics of the qualitative methodology and the research design are detailed in Section 3. Section 4 presents the theoretical framework and the data analysis. The paper concludes with discussion on the impactions of this work in Section 5.

\section{Composites and industrial growth}

\subsection{Light-weight design and black-metal composites}

Polymer composites are engineered materials that are composed of reinforcement fibres (made of carbon, glass, quartz, aramid etc.), and a supporting matrix (polymer resin) and offer undeniable value for various applications. The main advantage of these high performance materials is their ability to build highly customised products with unusual geometries along with the possibility to create non-uniform weight distributions, directional strength or stiffness. Examples of the use of composites can be found in the new Boeing 787 Dreamliner and the new Airbus A350. The majority of those aircraft structures is composite, lowering the structural weight of the plane and consequently consuming less fuel than existing airplanes in the same class. But the aerospace sector is not the only industry aspiring to decrease weight.

All manufacturers in general are pursuing light-weighting their products in response to environmental and energy supply concerns (Rightweight, 2011). Stronger and lighter products, signify less fuel for transportation, extended product life-cycles and less material disposed in the environment. However, what would an alternative material decision imply at the industrial level? The advantages that composites promise as technical material are major. It is the industry that seem to have difficulties to reach increased rates of manufacturing in order to maintain a sustainable growth model. Especially, when the development of the sector is shaded by the long standing metal tradition, prevalent in engineering design.

The case of the aerospace industry is a very typical one. In the early stages of application of composite materials the old knowledge and norms of metallic structures were utilised to design parts from carbon fibre. Those components, known as black aluminium parts (Tsai, 1993), were made from carbon composite to substitute an existing part with an almost identical design to the metallic part they replace. Overlooking the whole product architecture means that the new components are not realising the full potential that composites could offer. One might think that this is the first step in substituting an older technology with a new one. However, the same old design practices are still widely used across the breadth 
of composites applications (Potter, 2009), after almost half a century of composite design and manufacturing.

\subsection{Production capability and industrial practice}

Current manufacturing techniques and processes for composites are considered to have issues in terms of efficiency. Composite manufacturing is still dependant on a manual workforce to a great extent. This relates to the most common manufacturing technique required for aircraft applications, a unique case of assembling multiple layers of preimpregnated fibres on a mould, called lamination. Therefore human craftsmanship skills play an essential role in the quality and the production rate of composite components while an air of black art still exists around composite manufacturing (Elkington et al. 2013; Bloom et al. 2013).

Automated manufacturing processes appeared in the last decades; however they are still facing significant difficulties and problems related to affordability, process reliability and overall productivity (Lukaszewicz et al. 2012; Newell et al. 1996). A possible reason might link to the fact that the developers of those automated machines had in principle a background in robotics and automation of mainstream manufacturing processes, therefore neglecting the underlying complexities of a new material with distinctive manufacturing characteristics. Automations that take into consideration the complexities of composite manufacturing only recently started appearing. However, there are no automated processes currently available that can be used to manufacture relatively small and complex high quality components to increased production volumes.

As an example, those issues are reflected in the production capability of composites in the new Boeing 787 Dreamliner. Despite the use of automated processes, Boeing fell short in reaching the forecasted material laydown rate. More specifically, the production capability target of $200-500 \mathrm{lbs} / \mathrm{hr}$ proved to be unrealistic, while the actual production rate only reached $30 \mathrm{lb} / \mathrm{hr}$ by the time a report became available (Airbus SAS, 2008).

The corporate world has put significant effort in increasing composite production rates. Nevertheless reports of these efforts are not available, mainly due to the fact that organisations are reluctant to share evidence related with their performance. Official national and international statistical records regarding composite material are not available either. This is linked to the fact that composites pertain to a variety of sectors and therefore no single SIC code exists, as a consequence it is particularly hard to map composite activity and formulate reliable figures.

Composites by their very nature are not a substitution material, but a material with a radically different architecture to metal. For composites to be fully exploited the design and manufacturing philosophy should shift in a new direction along with industrial culture, structure and norms. In the next section the methodology we utilised to approach such issues is discussed.

\section{Methodology and research design}

The socio-technical nature of industrial growth, along with the lacking theoretical underpinning of material issues within the technology development literature, pointed toward a qualitative research approach. Rather than testing a hypothesis, we generated contextually rich data, looking at a broader range of interconnected themes in order to gain a deep understand of the role of composites in industrial settings. 
Table 1 Studied Cases

\begin{tabular}{ccc}
\hline Case No. & Industry/Sector & Activity \\
\hline 1 & Tidal turbine development & Prototyping, NPD \\
2 & Wind turbine blade & Design, Production \\
3 & Composite bridges & NPD, Production \\
4 & Composite skills development & Technical consultancy \\
5 & Composite build-to-print & Production \\
6 & Metal composite development & R\&D, NPD \\
7 & Composite build-to-print, mould making & Tooling, Manufacturing \\
8 & Aircraft equipment & NPD, Final assembly \\
\hline
\end{tabular}

This study is conducted from the perspective of the design - manufacturing interface in composite products and its impact on production capability. This interface is considered to be the context where composite product innovation takes place and thus is a fundamental point for industrial growth. The main research question is how this interface impacts productivity, and what can enable increased levels of yield in the sector. The focus of the study is both in the organisation level when this interface is part of the same organisation, but also in the inter-organisation level, whenever the interface is spread across different actors of the supply chain. Consequently, different aspects of the interface in the supply chain are included here. A more detailed examination of these aspects is described in (Chatzimichali, Potter and Smulders, 2013). The present paper will discuss the overall framework, developed through the investigation of eight industrial Cases in different composite sectors. Table 1 presents the sectors of those Cases and their main activity.

During this study, interviews were conducted with experts in Technical/Engineering Management positions. All the interviewees were male and hold or held in the past high-profile positions in plant management, production and engineering management and composite technical consultancy. Interviewees had an average amount of experience in the composite industry of 30.5 years, while 15 years was the minimum level of experience. In seven of the Cases they were based in the UK and in one Case in the Netherlands. The main material in all cases is carbon or glass composite, except Case 6, which is a unique case of industrialising metal matrix composites.

The interviews were in-depth, face-to-face and semi-structured in nature. They were based on a topic guide developed by the researcher to enable a detailed exploration of experts' views and experiences. The interview mean duration was two hours and in most cases took place in the industrial facility the interviewees were currently based in. The main subject of the discussion was the latest project or product, however many times they did reflect back on their previous experiences in the composites industry. The study was undertaken according to the guidelines of the Faculty of Science Research Ethics of the University of Bristol.

All interviews were audio recorded (total hours of interviews 17:07) and were fully transcribed by the researcher (total number of words: 101.241). The transcripts were initially open coded and then analysed using NVivo 10 (SQR International) qualitative data analysis software. A deductive line of work was utilised and the dataset was coded using a constant comparative approach. The next section presents the analysis of the qualitative data along with the developed theoretical framework. 


\section{Theoretical framework}

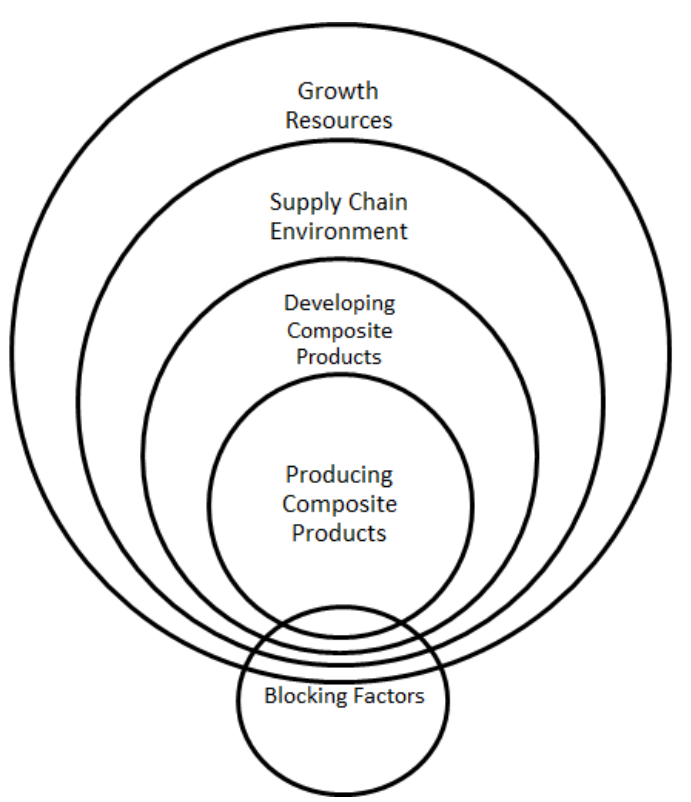

Figure 1: Integrative diagram of the theoretical framework

All themes emerged during the data analysis were classified in four categories: Producing Composite Products, Developing Composite Products, Supply Chain Environment, Growth Resources and Blocking Factors. Figure 1 illustrates an integrative diagram of the theoretical framework and demonstrates the connection between those five analytic typologies. Discussion structured according to those typologies is focused on the interlinked elements appearing in the dataset. In the subsections below the emerging themes are marked in bold text.

\subsection{Producing composite products}

The production of composites is one of the most dominant themes in the study since actual production volume is a fundamental measure of growth. This theme is associated with the way organisations increase their production capabilities. The main question here is how organisations involved in the manufacturing of composites accelerate production volume.

At the practical level, during the production process, the main mechanism behind increased production volume seems to be learning-by-doing:

Case 7: So the instructions in the shop floor, sometimes they are built up as you go. So the first part that is built in the shop floor, almost generates the instructions.

This potentially means that in composites production, the first manufactured part is crucial as it creates the actual manufacturing technique. This technique then gets recorded and acts as a map for the next part. The expert in same Case continues: 
Case 7: In the initial ones [meaning parts] you make perhaps a slight misalignment of the piece and what they will do is you will take it off and put it down again. [...] Because this is a big part of it, handling the material. How do they stick to each other, how do they react... can you move them, can you reposition, these are important learning that comes in from having done the job.

In this extract the actual learning process behind the manufacturing of a composite part is described. The manual handling of the material is fundamentally a very experiential process. The way a specific material is behaving in relation with the part geometry (and the mould) is probably the most important aspect of composite manufacturing and it is exactly the point where motor skill learning takes place. This immediate experience with the material and the understanding developed during the process are the main means to accelerate the production learning curve.

But handling the material is not the only experiential and craftsmanship point in composites. The development of the tool is another one. The mould or tool as it is usually called by practitioners, has a fundamental impact on production quality but also volume. Tool development for composites rests exactly in the middle of the interaction between developing a product and actually manufacturing it:

Case 5: In composite industry in general, first question you always ask is how do we make

it. How do we make it, what can we do. Can we make it? Do we need a tool? How many?

Case 7: Tool designers look at it and they have a feeling for where would you split, how would you do it. [...] There is no computer model which does that, not for us [...].

In tool development and material handling, it is the understanding of the workforce that is driving the process, rather than a standardised methodology. It appears that the industry greatly depends on those experiential and unstandardised processes. If this is the case, what could drive industrial growth? From the research perspective the answer would be gaining understanding about what makes those processes rely so much on experience and developing more concrete methodologies. However, practitioners seem to agree that the road to industrialisation comes through investment in standardised machinery and production technologies:

Case 5: [We are] Looking [for] a quicker way in cutting prepreg. So we are investing in a ply cutter, that will reduce the amount of time of the people cutting kits by hand. Once again small order, less investment.[...] We have invested in a five axis machine, multi surface machine. So we can say, what used to take 2 man-hours now takes 30 minutes.

This investment in standardised and generic production technologies is directly related with the magnitude of customers' orders. The order and the revenue it will create will enable an investment in a equipment that will facilitate manufacturing and make it cost effective, just like in every other industry.

However in Cases 3 and 2, where product development and manufacturing was in the same facility, there is a clear direction in industrialising the product-process combination to increase production volume:

Case 3: So you can see this [meaning the old manufacturing process] is a four-five six step process actually. This first bridge I have to do everything, I have been on it five months. One bridge. The way we make it right now is five days. [...] We did it by making serial productions, automated engineering and customer specific finishing. 
In those Cases both production processes were initially manual and the experts were working towards developing automated solutions. Nevertheless in Case 2 there were practical limitations that did not allow automation in the end. Product changeover was very difficult to be replicated by autonomous means, while quality defects that were easily identified and fixed on-line by the human operator, were very hard to detect and fix by an autonomous system. Consequently, no automated process could improve production rate and the organisation chose a different manufacturing strategy that is going be discussed later in this section.

Another theme that plays an important role in industrialising and increasing the magnitude of production is classic production engineer practices and tools. Production resource planning and allocation in general is very important in large volume production settings. ERP or MRP systems like SAP for production scheduling were mentioned, especially in cases with well-established products and customers.

Case 5: So productionisation [sic] is all about having enough resource in the right place with the plant equipment, machinery or persons to move that product quickly through the factory and out the other side.

This notion of production flow line is also fundamental in industrialisation and was highlighted in Cases 3 and 5:

Case 3: You really have to start thinking about the things that tend to move towards a bell or something which is a continuous process. A real continuous process. [...] You need to get serial production, if you don't make serial production you cannot be completive.

Case 5: It was one man doing one job and building one at a time. It was two people and they were delivering something in the end every six weeks. [...] So by the end of the time I spend sorting that product out, we were making one every six hours! [...] You break the job down. So you have one team making subparts. Which goes to another that assembles them. Which goes to another doing the final assembly.

This continuous production flow along with the division of activities is an essential tool in production engineering practice that contributes towards accelerated volume and decreased production time.

The upfront planning of resources in order to create a flow of activities is also related with preparing the parts (preforms) beforehand in order to save time from manufacturing. This preparation is product specific. The intermediary product is called a preform; preshaped part in a convenient geometry or pre-cut to suit the formulation of the mould shape. In many cases preforms are used as means to de-skill the manual fabrication process:

Case 3: We are taking a lot of work from the mould to a prefabrication facility. So we are making preforms that we can put in a mould, which is one of the steps that is here.

Case 5: The next stage beyond is preform the prepreg. So when the tool comes, just put the shape in.

Case 7: If you were receiving a preform for instance. Perhaps you can very quickly go down to a learning curve.

Preforms can be subcontracted or produced in-house. Subcontracting or outsourcing as a strategy is not limited to preforms or sub-parts but is also used in full products in order to increase the production capability in an organisation: 
Case 7: Say there was [a] 50.000 order, we would do the development work here and once we develop the process, document it and fully establish the process, we transfer that to one of our manufacturing partners.

Case 1: Say you are making one part and assembling. That will give you one level of capacity. If we then wanted to increase that then you have to subcontract some of your parts that will be manufactured outside and then just assemble. The capacity can go from $X$ to probably three times that.

Case 8: So there is real anticipation in increasing manufacturing volume. Expect for the intention to outsource more and more. So it is the same amount of people here would do more, because more has been done by external suppliers.

Going back to Case 2, where automation was not an easy option, the organisation used outsourcing as strategy to accelerate the production rate. The product was edesigned in order to outsource some of the subparts. The geometry was made simpler to decrease the amount of required materials and thus make production more effective:

Case 2: Conservatively expected 15\% to 25\% [meaning increase in production rate] because we could outsource some of the parts, geometry becomes simplistic, the flexibility was much much improved... [...] Again ironically we found as long as you looked from

their outboard, make it in more pieces was cheaper than make it in less.

In this Case redesigning and even increasing the number of components is paradoxically more cost effective when the new design allows to outsource the subcomponents. This attitude is the foundation of creating an integrated supply chain.

As a summary of the Producing Composite Products category, we would like to note that two main patterns were identified. On the one hand it was the craftsmanship approach due to intense learning-by-doing in manufacturing, material handling and tool development. Those elements along with industrialising the product-process combination seem to be very closely related with the nature of the composites industry. On the other hand, more traditional notions of industrialisation emerged through the themes of machinery and production technologies, production engineering practices as well as the concepts of production line, division of activities, preforming and outsourcing.

\subsection{Developing composite products}

Composites demand high levels of skills in different strands of engineering and scientific knowledge related with the material per se but also in-depth market insights. In practice Developing Composite Products is translated as a requirement for shared understanding between all the actors involved in their development.

Selecting a suitable manufacturing route and an appropriate material for the application is a combinatorial design problem. The process of making those combinatorial decisions is described as a mental loop to solve a mixed problem:

Case 3: It is a mixed problem. You have to adjust in both [meaning the design and the manufacturability] simultaneously. So actually when you sketching something like this or

like that [pointing at some of their products], in your mind you are making a loop, checking the mechanics to production in size, the injectability and then you go back, then you go back... it is not one step.

Part of this combinatorial design problem is the definition of manufacturing process parameters that requires deep knowledge of the material and its processing. Those combinatorial decisions need to be made during the early stages of development, since they deeply impact the functional behaviour of the product. 
Case 1: The big problem has always been with composites that you are manufacturing your own material as you go along and there are an infinite combinations of fibre, resin and process for that matter or temperature you process.

Unlike processes in other fields than composites where production parameters are predefined and fine-tuned in practice, in composites controlling these parameters is part of the product development process. It is also very common different supply chain partners to perform only parts of this complex process. As a consequence, setting process parameters along with the control over product development are many times split across the supply chain. This brings a collaborative dimension in product development decisions.

Case 6: You have to work with the customer to understand not the specification of the current part, but what the requirements of the system are. Very very important, but very difficult to do.

This collaborative and combinatorial nature of development might also partially explain the high number of manufacturability iterations that seem to be a common practice in many cases:

Case 5: [We are] having a drawing, which lands on the desk to make something in composites and then the composite manufacturing engineer has to take it apart. Take it apart and discover how to make it. [...] So what we have to do really is to change their [meaning the customers'] drawing. Change their model to what can be made. And that does happen, it happens quite a lot.

The term discover in the above extract brings an element of revealing something anew every time. The manufacturer is making an effort to identify what is behind the drawing in order to create a practical way of making the part. This process has also been described in Case 8 from the other end of the line:

Case 8: It is this process of creating a requirement and giving it to a supplier, a manufacturer and imagine that everything you need is in that requirement, but it isn't. The supplier has to have an input, because you don't know everything about that part without supplier input.

Manufacturability iterations happening during the development phase can also impact the product architecture. For example here the whole product had to be re-engineered in the level of specifications:

Case 1: Somebody designed the whole machine, then came to us for the blades, so he said to us, this is the geometry, this is the load and we said you have to change that, this is too difficult. So they changed the geometry, they changed the loads and finally we said okay.

A possible explanation for the level of manufacturability iterations seems to be the lack of "Design for Composites" mind-set, which also extends to a lack formalised "Design for $\mathrm{X}$ " type of methodology. In Case 5 this is discussed from the supplier's perspective for two different products:

Case 5: They [meaning the designers] will put high tolerance finish on the back face of the product. Aerodynamic face. Yeah! Understood. You need it. The back face? Don't give me a tolerance. It will not be measurable.

So we send it [meaning the drawing] back to the customer. We said you cannot do this. If you don't have a product line in the middle you cannot have a product of that shape, we just cannot do it. 
At this point, it worth noting that in more standardised components (e.g. aerospace), where the design is pre-determined, there are no such iterations. In those case manufacturability iterations are not common, while material selection and consequently manufacturing routes are dictated by the clients. However, this does not imply that the product is actually optimised for manufacture, merely that it is fixed by the client for good or ill, with significant cost and quality implications.

There are many different manufacturing process for composites. In less standardised products and components, an important point in their development is the definition of the manufacturing route. It is a highly empirical process, while the decision requires high levels of expertise that is only built through practice:

Case 7: This is a difficult one, I am not quite sure how we do that. I think a lot of it comes down to experience. And I think we say, we evaluate this and then we do this and then we do this. In reality quite often it comes as a flash and it is, yes we want to make that and that could be made up like this. You know they come up with the concept very very quickly, based on experience.

A theme very closely interweaved with the definition of the manufacturing route is material selection since the first feeds back into the second. This can be a complex decision, while also it might require the creation of the design allowable data for the particular application. As a consequence, smaller actors only deal with a limited amount of material types, which they have previous experience with.

Case 7: Big companies, they have a huge database of specifications and performance characteristics so they are fine. It is really in dealing with the smaller customers, the new customers that they don?t have those data available so that is more difficult. Definitely! And of course generating the design allowable for these materials is an expensive job. And that is not always available.

The lack of design allowable data acts as a limiting factor during material selection. Especially in aerospace applications, where safety regulations impose restrictions and the cost of material qualification is great, new materials are generally avoided.

Case 5: With the commercial product very often [we] have an input into that, say we can do it in an alternative material. We have offered and are offering alternatives material for aerospace products, but there has to be requalification which is a huge cost to the customer to get approval to use that different material.

Case 8: Our problems with the materials are more in terms of certification. What material is acceptable to our customers, so many reasons would be or set by our customers.

Both those extracts describe a similar attitude towards alternative material and material qualification limits their choices. On the other hand in Cases like 1 and 6, where there is a novel application and the material is not yet established, organisations have to go through the material accreditation process in order to industrialise the product:

Case 1: You need design allowables, you need to know what you can expect the material to do both in static terms (static track) and also its fatigue properties in our case. [...] Problem comes; of course, you need all that because when it comes to certification, the certifying authority will want to know the source of your reliable data 
Summarising the Developing Composite Products category, it is evident that the idiosyncratic nature of composites, sets them apart from products in other industries that have more standardised ways of decision making during their development phases. The combinatorial design is an umbrella term for setting manufacturing process parameters, defining manufacturing routes, material selection and qualification. Whereas the collaborative dimension of composites development is connected with the sharing of decisions with other supply chain partners, where manufacturability iterations and the lack of Design for Composites mindset greatly impact this process.

\subsection{Supply chain environment}

The Supply Chain Environment is the setting where the two previous typologies, Production and Development of Composite Products, are nested. But what exactly is part of this environment? The composites industry appears to be a whole industrial ecosystem, consisting of organisations from different industries and very diverse markets.

Case 4: When you look into composites industry what do you see? Do you see people making septic tanks? People making formula one bits? The aircraft makers? You don't see it as one thing and because you don't see as one thing, there is a lot of hidden prospects but also a lot of hidden challenges.

This diversity of products and markets is the root of inhomogeneity in the composites sectors. Some of the interviewees had rare work experience in diverse sectors of composites and discussed the different market drivers. For example, the expert in Case 3 is an aerospace engineer by trade, while his organisation is currently focused on the civil engineering market. He discusses the different market drivers between the sectors:

Case 3: In aerospace it is top down, so you have the highest quality and price is a result of that. While in civil engineering you will not sell a bridge in composites even if it better than a steel or concrete bridge if it is one euro more expensive than the steel or concrete. [...] So when you start with composites in civil engineering you always start with the cheapest material.

In the aerospace market the main concern is the weight of the structure, while in civil engineering the cost of the material play the primary role. However as the expert in Case 8 points out, weight in aerospace is indirectly translated as cost:

Case 8: We are looking at the cost to be maintained but the mass should [be] reduced. And we want the mass to be reduced because we get a penalty that we exceeded to that. So it is cost in the end but then we call it mass.

In the Case 2 the wind energy industry is compared with the aerospace industry:

Case 2: The biggest problem in the wind energy industry is manufacturing rate, everything comes back to rate. Unlike aerospace which is much more driven by weight, rather than rate because that drives the cost.

Here a comparison is made between the aerospace driven by cost/weight and the wind energy industry that is driven by manufacturing rate. Different market drivers have a direct influence in the material used in practice during product development. The expert in the next Case is one of the exceptional cases with work experience in multiple industrial sectors of composites. He has deep knowledge of the different markets and their fundamental influence in the way products are developed. Here he discusses the general beliefs of the different composites sectors: 
Case 2: There is an awful lot on arrogance within every, every(!) industry. Civil for example believes that no one else understands the financial drivers that they are under. Nobody can make it cheap enough for them to be interested. Aerospace believes that their quality is by far and away higher than anybody else, which is fair enough. But as a consequence they cannot learn a thing by anybody else. Wind energy, they are so efficient, not quality but their efficiency is so high that they laugh for the aerospace industry that it took so long for them to do anything. And the marine industry is kind of like we have been doing this for anybody else, so it is up to us.

Knowledge and skill transfer among the sectors are important ingredients to build common ground and develop an integrated supply chain. In most cases experts agree that this cross-sectoral knowledge transfer is lacking.

Case 7: I think there is a common understanding. I am not sure how far this goes in the smaller [meaning companies]. You know, if you move away from the aerospace sector. And you move out into the general manufacturing, I don't think this is so much the case.

Shared understanding exists only between the big aerospace companies, where the products and processes are standardised. It can be attributed to the relatively small size of the sector in the UK that enables personal connection. In other sectors this is not the case.

An exception regarding cross-sectoral knowledge transfer would be a supply chain building exercise that took place in the UK. Unfortunately, smaller players cannot afford the time to take part in similar activities and consequently miss those benefits.

However, the reluctance to share knowledge and adopt a collaborative attitude was not only a cross-sectoral characteristic. Below the approach of a smaller (Case 5) and a bigger (Case 2) actor in the sector regarding collaboration are discussed:

Case 5: We don't openly go out and see methods that are used in another [meaning industry]. The general manager and business development manager have a lot of knowledge about what there is in the business about new techniques and knowledge, new application and we can discuss if a new technology can make the part.

Case 2: Because they [meaning the wind energy company] are so paranoid about IP [Intellectual Property] they always have done all their learning in-house and they kicked it away from anybody else and they are prepared to buy in experts. They were very happy to buy people to employ them to do their job. But they won't join forces with other people to do it.

This distant relationship of the supply chain actors with their existing clients and suppliers was explored in many other cases too. In Cases like 6, and 1, where new material technologies are developed in-house and intellectual property rights are crucial, there is a very protective attitude towards the technology.

Case 6: We can work with a customer that wants to develop a part, but it is actually their clients who are buying the part that you are telling them what it goes into production. Then we have to be carefully that we protect our options, that if they cannot sell it to their customer, we still have the potential to market it to somewhere else.

Those increased levels of complexity in the supply chain add a layer of obscurity and potential distrust or protectionism. In Case 1 they prefer to keep the client at a distance, while the role of role of intellectual property again seems to contribute to this distrust: 
Case 1: We keep them [meaning the customers] vague, because it is important for us to own the IPR [the intellectual property]. We can't let our clients own the IPR because that will be a disaster. They would insist, it's just them and nobody else can have it. [...] Because composites are new, they [meaning the big players] see IPR floating around, know-how expertise and they want to grab it and own it.

Case 4: The larger companies are just voracious in terms of intellectual property and wish to control it.

Case 8 is an excellent example of a difficult client - supplier relationship. The segmentation of the supply chain is reflected in the extract below:

Case 8: Initially we got one subcontractor to design it, another subcontractor to build it, which is an extremely poor approach. And we weren't involved into either; we were just involved in the specification. And that is proved to be very problematic, that is an example of non-successful, it hasn't completed, it is taking a long time and I would say that it's a hard moment.

The quality of this relationship is reflected upon the dialogue between the actors:

Case 8: What we are finding is that we need to put the dialogue parts of the sourcing process into the process. It cannot be incidental. Or it cannot depend on whether people choose to go to the supplier and talk to them. It has to become part of the process of sourcing composites in order to make the job more smoothing and the outcome more acceptable.

Here the importance of formalising the operational process to ensure a close connection with the supplier is highlighted. In this case the organisation already had experience in a variety of non-composite products. However, this relationship between the supply chain actors has the potential to be particularly problematic especially for composite products:

Case 8: It is because of insufficient preparatory work. Insufficient dialogue. It is going straight from the intent to the design and that doesn't work. It doesn't work on most things, but it particularly it doesn't work with composites. [...] And in the case of composites, that method doesn't work very well, because all information is within specification, because the specification doesn't recognise all the problems associated in making composite parts.

Communication issues are initially attributed in insufficient preparatory work. The approach to create the product specifications in composites seems to be inadequate to convey the right amount of information in order to mitigate problems. But beside the technical aspect, when issues arise the social part of the relationship is also affected. The contractual nature of the relationship and the direct impact on product quality are discussed below:

Case 8: If the manufacturer who was doing the detailed design of [the product] had said to us "this is a difficult area and we'd like to look at it again" and we'd look at more detail and we'd said "okay actually this area is not loaded them, we can review the loads" and so on. There wasn't that discussion. It was passed on. [...] There was friction between the two design teams, real bad feeling, blame and so on. The thing turned out heavier, it is far too thick and it is extremely expensive.

Summarising the Supply Chain Environment theme it important to note that issues regarding the distant relationship between the actors were very dominant. Those issues are amplified by the inhomogeneity in composites sectors, along with different market drivers and the lack of cross-sectoral knowledge transfer. As a result instances of distrust and friction appear in the supply chain. 


\subsection{Growth resources}

The term Growth Resources describes the means, as they are currently perceived by experts, that facilitate industrial growth in composites.

The role of a guide-spot in the development of the industry was a theme emerged during discussion. More specifically, the recent foundation of the National Composites Centre (NCC) in the UK (established by public funding) and its perceived role was discussed:

Case 7: [the NCC] is a common ground where they can all come together to work. So people can go there with a requirement and the team can call various suppliers and experts and give solutions to your problems. So I think that this can potentially work well.

However issues of trust, considerations regarding its role, and the thematic orientation of its activities were criticised:

Case 1: So the problem is that it [meaning the NCC] becomes too commercial. The NCC is run by the big or half a dozen big companies. And I am convinced that they are out there, there are for any IPR games that they are making.

Case 6: Well the starting comment is, you come in we do some work with you. We share it with our big partners, but our big partners will not let us share what they are doing.

Case 7: I think it is expensive if you don't have an absolute requirement for it. If you are a company like us and you are used in relying in your skills and expertise then why go to the NCC. [...] So there is an awful lot of money being invested in high-end automation of composite production, which is fantastic, but of course only the very big boys can afford it.

The organisation in Case 5 is part of NCC. One would expect them to be able to articulate the benefits, but they also recognise that the technology gap prevent their growth:

Case 5: The NCC has modern equipment. As a small company we can access that in order to make figurative products. Hopefully, if we can make those products, we can then expense on our own machines or technology. But there is still a big gap. The big cost of the machines, which prevents that transfer.

The expert continues claiming that "learning is a bit one sided" possibly meaning that the Centre's attention is given to the learning needs of bigger players.

Public investment is one face of the coin. Attracting supply partners to help in industrialising a product or a new technology is the other. Especially when novel technologies are developed, the role of the first client (or champion) is pivotal. A successful example is Case 3:

Case 3: The engineering bureau of the municipality of Rotterdam, if they say it is good, all the other municipalities will accept that is good. And in fact that is exactly what happened. Before that there was no reaction from the market. When we did this bridge they put some people from the municipality here in the company to check the calculations, the production technique and at some point they gave their blessing! [...] So you are very dependent on a champion within the people who give you orders. And if you have no champion you will fail with the basic cost price argument.

Case 6 and 1 are in different phases regarding this relationship:

Case 6: There are companies that we spoke with about different elements of the process who would love to partner with. They are interested but they need to know that there is a market in place, which I cannot guarantee at the moment.

Case 1: The problem is I couldn't find anyone to get this product to production. Yes, because it is a very difficult business to make money. 
In Case 6 the organisation is still seeking for this champion, while in Case 1 a product was abandoned because they couldn't find the champion to industrialise it.

More general issues regrading the investment attitude were also discussed. In Case 2 the expert's opinion is that the industry is not prepared to invest to further industrialise, while in Case 4 the expert indicates that smaller organisations do not have the means for this investment:

Case 2: People [in composites] moan that it takes too long for people to take things from a theory to practice. But it takes so long because nobody is prepared to invest.

Case 4: If we can move and focus on their manufacturing techniques and away from a predominantly manual concept, then the world changes. Now that's not just a question of thinking it is a question of investment, so I think many small companies don't know what they don't know because they cannot afford to find about it.

The same attitude towards investment to research is relevant in Case 4:

Case 4: My CEO would tell me that for that amount of money you would make the product yourself. You don't have to put that amount in a pot to be told how to make it. [...] We don't have to research it, we just have to make it.

Another aspect of investment was also explored in Cases 6 and 3. The discussion moved around attracting investors (venture capitalist) to finance the company in order to industrialise a novel technology. The initial investment to build the technology and develop the market, along with the difficulties regarding attracting investors were discussed. Here investors see a risk in composites and are reluctant to invest:

Case 6: To grow we have to look attractive enough to get that investor in.[...] And UK investors don't particularly like industrial investment because they spend a lot of money on a special kit, that if it goes wrong they have got a pile of scrap metal.

Case 3: Even the banks they supply with a loan, but don't take risks, you can get a commercial loan. [...] Actually everything we do is unique, nobody did this before. And it is not innovative enough [to get government funding]? It has to do with what is being subsidised in Holland. This is production industry. Production industry is not sexy. They want to support nanotechnology, IT everything that has nothing to do with production.

Cases 6 and 3 are based in different countries. However the legislation regarding investment in manufacturing seems to have considerable similarities that do not facilitate growth in composites technologies in either Case.

The predominant theme around the Growth Resources is investment and the attitudes related to it. This can be government investment in the form of a guide-spot or private investment the role of the first client (champion) that will facilitate the industrialisation of a new product/technology.

\subsection{Blocking factors and conditions}

Blocking Factors and Conditions is a theme overlapping with all the themes that were previously discussed in this paper. Here, we will summarise all the concepts that appear to impede the industrial growth of composites.

One of the most important resources for growth in every sector is the development of the workforce with the right skills. According to the experts, the lack of composite skills is one of the major factors that limits the growth of the composite sector. It is a theme that was raised in almost all the cases: 
Case 1: Very few engineers, still, know how to design and make it as a means [...], [composites are] still not totally understood.

Case 7: It's really difficult to get skilled people. [...] One of the biggest problems is supply of labour so getting the people to do the work.

Case 5: Resource with hand skills. Hand lamination. We cannot get people with the right skills. [...] So we are going to get young persons involved because we cannot find experienced people. So these are the two things at the moment. Resource with skills.

In Case 4, an argument regarding the difficulty to develop composite skills in the current technological environment was presented:

Case 4: Before there used to be a sequence of research and development, product development, industrialisation, sell it now, bring the work force in. You know you can imagine how long this can be. But now it takes less time to industrialise a product than it does to develop the people to make them.

Composite technologies seem to be moving forward faster in relationship with the skill development aspect in the industry. Composites skills are a rather complex mix of motor skills for manual layup and material handling, design methodologies, mould making techniques and (material-related) practical but also theoretical knowledge. The expert in Case 4 quantifies this lack of skills:

Case 4: The industry, by general acknowledgement is short of 20\% - 25\% of people. [...] So in theory this means that this business is constrained by $20 \%$ of its growth capability. And that's because the people that aren't coming out of the system with the right skills and because the labour pool is small.

Here implications about the educations system and the size of the labour pool are made in an attempt to identify the root cause of low skills. However, during the study there were strong indications that composites skills are improving. This potentially means that the industry is on the steep part of the learning curve while more workforce is being trained.

This lack of skills in composites seems to be directly related with the lack of a Design for Composites methodology discussed in the Developing Composite Products theme, but also the metal mind-set that is prevalent in engineering design practice. In Case 5 there is an extensive mention on the practical skills required to make the designer think more in terms of composites:

Case 5: It is difficult to get a designer to change his mind, to think such as a square corner. A square corner is no good with composite, it needs to be rounded to take the stresses away from the corner and still have a lot of hard corners drawn in a composite component. So when the designer gives you a nice sharp angle on a composite component there be no composite component [meaning that this component could not be manufactured]. [...] They still apply the same tolerances to a part on composites, which we will then say no! You cannot do that! You can't have this tool face and that as a tolerance.

However, the metal mind-set is not only limited in engineering design but also impacts the interface with the clients. Below client expectations are also discussed:

Case 7: They [meaning the client] know they have to reduce weight to improve economy [of the part], or improve the centre of gravity or the stiffness or some parameters they have to change, and they want to go to a composite part and then they are surprised by the cost of the composite part. And of course they don't really looking at the whole picture. [...] Their expectation is wrong, but they don't take into consideration all of the processes to go into making a composite part. 
Beyond the practical level, in Case 7 the level of academic training of engineers in composites was considered:

Case 7: If it was in metallic industry, you go to an engineering university and you got taught about materials. You go out to the workplace and you know how to apply those skills and make metal parts, forgings, castings, sheet metal parts. In the composites industry it is kind of different thing. [...] People have entered it from other engineering backgrounds and disciplines and have learned on the hoof if you like, about processing composite material and then there are a few clever designers who have come through the academic route.

Another important blocking factor is the operational inertia that some organisations demonstrate towards composites by insisting to use the old processes even for a new material. In Case 2 the unwillingness to switch the design philosophy in another material than metal, inside an organisation is discussed:

Case 2: There we are basically looking at how to speed up the production, without changing the design philosophy from metallic aircraft, it was very difficult to achieve. So we were using the same design philosophies we were using the same configurations and we were trying to make the composite solution fit. [...] So effectively we are following a design that dates back to the early sixties and try to repeat exactly what we were doing but with a different material.

The way activities and tasks are structured inside an organisation and the decision making points in the existing processes might not be appropriate for a new material. In the same case, the expert is also arguing on a similar experience in another organisation:

Case 2: They had certain way of manufacturing something, we were proposing a new design, but they were just asking us to make sure that the new design to be able to be manufactured in the old way. The point that we were fighting was that the new design could be made in a different way which could be potentially easier than the old way.

Those old operational processes that used to work well with other materials, fail to do so with composites. The client/supplier friction in Case 8 (discussed in 4.3), also seems to be caused by this operational inertia:

Case 8: In the case of composites, that method doesn't work very well, because all information is within specification, because the specification doesn't recognize all the problems associated in making composite parts?

A final point regarding the blocking factors in the industrialisation of composites is the craftsmanship approach in various aspects of composites (as it was already discussed in 4.1). Manual lamination is highly dependent on motor skills, tool development is created according to the "feeling of the designer". Even choosing the manufacturing route comes as a hunch: "in reality quite often it comes as a flash and it is, yes we want to make that and that could be made up like this". Those characteristics describe an approach where the craftsman, just like an artist, applies his individual skills in making unique items of a variant quality. In industrialised processes on the other hand, increased levels of knowledge are applied in order to predict the behaviour of the product in manufacturing and establish high degrees of standardisation especially regarding quality.

The Blocking Factors and Conditions in the composites industry seem to be rooted in the lack of composites skill and education related with the very nature of the material. This seems to trigger the second level of factors. There are the metal mind-set, operational inertia and the craftsmanship approach and all seem to be connected with an industrial system that has not yet gained momentum during a technological transition. 


\section{Concluding thoughts}

Even though very strong expectations in composites were formed since the '80s (Carlson, 1993; Harris, 1991), the shift of increased production capability has yet to come. This work is a socio-technical interpretative approach to this seemingly low production capability. A critical study of the technology development literature indicated that composites, as a material technology case, do not follow existing theories. Hence, the objective of this paper was to develop a theoretical framework to support our understanding of industrial growth for composite material technologies. Expert interviews and further analysis of qualitative data led to the formulation of an overarching framework, outlining issues around the design and manufacturing of composite products. The framework was established on four emerging thematic categories: Producing Composite Products, Developing Composite Products, Supply Chain Environment, Growth Resources and Blocking Factors. This framework is based on rather flexible conceptual terms that are directly connected with raw data, not on rigid theoretic variables and causal relations. Although it certainly has limitations, it provides in depth insights on the industrialisation of composite material products and manufacturing strategy concerns.

The next question to ask is whether the emerging themes are sketching the root causes or simply the effects of inertia for change in the field. For example, is the lack of composite skills the reason behind low production volume or simply the effect? Do the right skills proceed technological changes or they follow them? Considering that innovations are separate from the current socio-technical regime (Geels and Schot, 2007), one might conclude that skills arise after the transition and grow due the industrial momentum around a technology. Consequently, the lack of momentum in the composites socio-technical environment might be the underlying reason of low skill in the sector. Even if resources or the right skills magically appear in the system, there is increased possibility not to get properly utilised. The reason is that an immature industrial environment cannot absorb new technologies, when integrated and embodied knowledge is in shortage (Stigler, 1951). This knowledge can only be developed by a combination of formal educational and practical expertise. Therefore, the solution does not rest in automation or practical skills as such, but in progressive development and establishment of the capability to build the skills, the integrated knowledge and the new operational processes around composite technologies.

Considering the history of material in aerospace, the sector that played a fundamental role in composites, Schatzberg (1998) discusses the reluctance to composite innovation and questions the laws of natural selection for new material technologies. No objective processes ensure that the best technology will prevail. Instead, progress comes part from reasoned argument and empirical evidence, and part from the symbolic meanings shaping technical culture. In these terms, the first step to gain industrial momentum in composite material technologies is by becoming convinced that they are an indispensable part of a sustainable future.

\section{Acknowledgements}

This research was supported by the EPSRC Centre for Innovative Manufacturing in Composites. 


\section{References}

Abernathy,W.J., Utterback, J., (1978) Patterns of industrial innovation, Technology Review, Vol. 50, Issue 7, pp. 41-47.

Airbus SAS. Boeing 787 - lessons learnt (2008) Available at: $<$ http://www.planebusiness.com/buzz/airbus2.pdf>, Date accessed: 20/6/2015 .

Anderson, P., Tushman, M.L. (1990) Technological discontinuities and dominant designs: a cyclical model of technological change, Administrative Science Quarterly, Vol. 35, No. 4, pp. 604-633.

Anderson, P., Tushman, M.L. (1991) Managing through cycles of technological change, Research Technology Management, Vol 34, No.3, pp. 25-30.

Bloom, L.D. Elkington, M., Ward, C., Chatzimichali, A., Potter, K. (2013) On prepreg properties and manufacturability, Proceedings of the 19th International Conference on Composite Material, pp. 4397-4404.

Carlson C.W. (1993) Polymer composites: Adjusting to the commercial marketplace. The Journal of The Minerals, Metals \& Materials Society (JOM), Vol. 45, No. 8, pp. 56-57.

Chatzimichali, A.P. Potter, K.D. Smulders, F. (2013) Understanding the NPD-Production interface: advanced industrialisation and growth in the composite industry, Proceedings of the 14th International Continuous Innovation Network Conference, pp. 198-209.

Elkington, M. Bloom, D., Ward, C., Chatzimichali, A. P., Potter K.D. (2013) Understanding the lamination process, Proceedings of the 19th International conference on composite materials, pp. 4385-4396.

Geels, F. W., Schot, J. (2007) Typology of sociotechnical transition pathways, Research Policy, Vol. 36, No. 3, pp. 399-417.

Harris, B. (1991) A perspective view of composite materials development, Materials \& Design, Vol. 12, No.5, pp 259-272.

Linton, J.D., Walsh, S. (2008) A Theory of Innovation for Process Based Innovations such as Nanotechnology, Technological Forecasting and Social Change, Vol. 75, No.5, pp. 583-594.

Lukaszewicz, D.H.J., Ward, C., Potter, K.D. (2012) The engineering aspects of automated prepreg layup: History, present and future, Composites Part B: Engineering, Vol 43, No. 3, pp. 9971009.

Murmann, J. P., Frenken, K. (2006) Toward a systematic framework for research on dominant designs, technological innovations, and industrial change, Research Policy, Vol. 35, No. 7, pp. 925-952.

Newell, G.C., Buckingham, R.O., Khodabandehloo, K. (1996) The automated manufacture of prepreg broadgoods components - A review of literature, Composites Part A: Applied Science and Manufacturing, Vol. 27, No. 3, pp. 211-217.

NVivo qualitative data analysis software; QSR International Pty Ltd. Version 10, 2012

Potter K.D. (2009) Achieving low variability, rework and scrap rates in the production of advanced composite parts, SEICO09, 30th SAMPE Europe, pp. 265-270.

Rightweight (2011) Edited by Geoff Hollington, Published by Materials KTN, UK.

Saviotti, P.P., Metcalf, J.P. (1984) A theoretical approach to the construction of technological output indicators, Research Policy, Vol. 3, No. 13, pp. 223-233.

Schatzberg, E. (1998) Wings of Wood, Wings of Metal: Culture and Technical Choice in American Airplane Materials, Princeton University Press.

Stigler, G.J. (1951) The Division of Labor is Limited by the Extent of the Market, The Journal of Political Economy, Vol. 59, No 3, pp. 185-193.

Tsai, S.W. (1993) Rules of Composites Design: A Review in Metal Matrix Composites, Proceedings of the Ninth International Conference on Composite Materials (ICCM/9), Vol. 1, Woodhead Publishing.

Utterback, J., Abernathy, W. (1975) A Dynamic Model of Product and Process Innovation. Omega, Vol. 3, pp. 639âŁ“656 
Utterback, J., Suarez F. (1993) Technology, competition and industry structure, Research Policy, Vol. 22, Issue 1, pp. 1-21.

Tushman, M. L., Rosenkopf, L. (1992) Organizational Determinants of Technological Change: Towards a Sociology of Technological Evolution. Research in Organizational Behavior, Vol. 14, pp. 311-347. 